\title{
The Standardization Process as a Chance for Conceptual Refinement of a Disaster Risk Management Framework: The ARCH Project
}

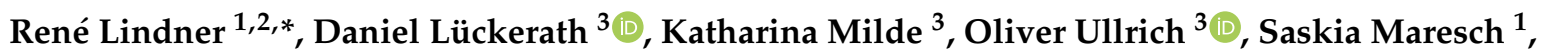 \\ Katherine Peinhardt ${ }^{4}$, Vasileios Latinos ${ }^{4}$, Josune Hernantes ${ }^{2}$ and Carmen Jaca ${ }^{2}$ (D) \\ 1 DIN German Institute for Standardization, 10787 Berlin, Germany; saskia.maresch@din.de \\ 2 TECNUN Escuela de Ingeniería, Universidad de Navarra, 20018 San Sebastián, Spain; \\ jhernantes@tecnun.es (J.H.); cjaca@tecnun.es (C.J.) \\ 3 Fraunhofer Institute for Intelligent Analysis and Information Systems IAIS, 53757 Sankt Augustin, Germany; \\ daniel.lueckerath@iais.fraunhofer.de (D.L.); katharina.milde@iais.fraunhofer.de (K.M.); \\ oliver.ullrich@iais.fraunhofer.de (O.U.) \\ 4 ICLEI Local Governments for Sustainability, 79098 Freiburg im Breisgau, Germany; \\ katherine.peinhardt@iclei.org (K.P.); vasileios.latinos@iclei.org (V.L.) \\ * Correspondence: rene.lindner@din.de
}

Citation: Lindner, R.; Lückerath, D.; Milde, K.; Ullrich, O.; Maresch, S.; Peinhardt, K.; Latinos, V.; Hernantes, J.; Jaca, C. The Standardization Process as a Chance for Conceptual Refinement of a Disaster Risk Management Framework: The ARCH Project. Sustainability 2021, 13, 12276. https://doi.org/10.3390/ su132112276

Academic Editors: Leire Garmendia, Alessandra Gandini and Gemma Garcia Blanco

Received: 4 October 2021

Accepted: 4 November 2021

Published: 7 November 2021

Publisher's Note: MDPI stays neutral with regard to jurisdictional claims in published maps and institutional affiliations.

Copyright: (c) 2021 by the authors. Licensee MDPI, Basel, Switzerland. This article is an open access article distributed under the terms and conditions of the Creative Commons Attribution (CC BY) license (https:// creativecommons.org/licenses/by/ $4.0 /)$.

\begin{abstract}
Risks related to climate change and natural hazards increasingly affect urban areas such as historic towns, old urban quarters, villages, and hamlets. These, as well as historic landscapes, make up a significant part of an urban area's identity and cannot just be rebuilt or significantly changed without taking into account the historic value, cultural background, and prescribed regulations. Systematic resilience building for historic areas is becoming essential, and research supporting it will be in the spotlight. However, questions still exist concerning how to best transfer research results into practice at the community level. Standardization of resilience-enhancing methods and tools deriving from research projects is one option, chosen, e.g., for the EU-Horizon 2020 project ARCH. Within the project, a disaster risk management (DRM) framework has been composed and then transferred into a standard, supported by a co-creation approach involving relevant stakeholders. This article outlines the project's different standardization steps and its impact on the development of the ARCH DRM Framework. It highlights the systematic inclusion of project-external stakeholders who actively contribute to the validation and enhancement of the ARCH DRM framework to guarantee maximum applicability in historic areas, supporting them in their fight against the impacts of climate change and natural hazards.
\end{abstract}

Keywords: standardization; city resilience; case study; historic areas; disaster risk management; research projects; culture heritage preservation; climate change adaptation; technology transfer

\section{Introduction}

Significant parts of Europe consist of historic towns and city centers as well as cultural landscapes: natural heritage sites cover roughly $18 \%$ of the European land territory [1], and, on average, $22 \%$ of the European housing stock was constructed before 1946 [2]. These historic areas, which often do not meet the evolving needs or standards for resilience [3], are embedded in larger urban and rural environments, serving a role in preserving local identity and personality as well as local knowledge.

Currently, historic areas all over the world are put in danger by the accelerating threat from climate change, with natural disasters becoming more frequent and their impacts becoming more severe, especially for countries with developing economies and their (urban) heritage [4,5]. Additionally, although climate change has become one of the most significant and fastest-growing threats to people [6] and their cultural heritage [7], the impacts of climate-related and other natural hazards on historic areas have not been studied 
extensively [8-10], even though disaster risk reduction is a priority in the management of World Heritage property [11].

Therefore, there is a need for frameworks, methods, and tools that provide better information and decision support for climate change adaptation and disaster risk reduction measures taken by heritage managers, urban planners, policymakers, and the general public. These frameworks need to take into account the unique physical, environmental, economic, social, cultural, and political aspects of historic areas, as well as the enabling conditions these areas provide for taking action. Additionally, they need to be supported through stronger promotion of relevant public policies and participatory governance processes that facilitate the active participation of citizens from local communities and the general public. Overall, climate change impacts on historic areas merit wider attention and urgency, and resilience-enhancing strategies need to be included in heritage management policies and practices. At the same time, the role of heritage in climate change adaptation and disaster risk reduction within the wider urban context has to be emphasized.

The fields of disaster risk management (DRM) and climate change adaptation (CCA) both of which are important pillars for a community's or city's resilience-are growing closer together (see for example the Fifth Assessment Report of the Intergovernmental Panel on Climate Change (IPCC) [12]). Therefore, the overarching topic of resilience has been put even more on the forefront of local, national, and international policy frameworks and initiatives. The Sendai Framework [13], the Paris Agreement [14], and the Sustainable Development Goals [15] form part of the international policy foundation for resilience, while initiatives such as the Rockefeller Foundation's 100 Resilient Cities [16], the Resilient Cities Network [17], and the United Nations Office for Disaster Risk Reduction (UNDRR) with the Disaster Resilience Scorecard for Cities [18] provide resources for local implementation of resilience.

There is not just one single definition of 'resilience'. It can take different forms depending on the context in which it is applied (see, e.g., $[19,20])$. In general, three different understandings of 'resilience' can be distinguished: engineering resilience, ecological/ecosystem and social resilience, and social-ecological resilience (see, e.g., [21]). Engineering resilience aims to withstand shocks and return to a stable pre-disaster state as fast as possible ('bouncing back', see, e.g., [22]). Ecological/ecosystem and social resilience (also known as 'multi-equilibria-resilience' [21]), on the other hand, acknowledge that a disturbed system might not always return to the same stable pre-disaster state and aim to adapt the system to better cope with the disaster ('bouncing forward'). Social-ecological resilience, in contrast, takes a dynamic perspective where social and ecological systems are seen as linked and co-evolving ('evolutionary resilience' [21]). Here, resilience is treated as a process that needs to account for uncertainty and flexibility, learning, and advancement of the capacities and abilities of a system to withstand future shocks. This is also the view taken by the IPCC in their Fifth Assessment Report [12], where resilience is defined as "the capacity of social, economic and environmental systems to cope with a hazardous event or trend or disturbance, responding or reorganizing in ways that maintain their essential function, identity and structure, while also maintaining the capacity for adaptation, learning and transformation". However, the system focus of the IPCC definition fails to explicitly link resilience and justice, obscuring that impacts of climate change and natural disasters are experienced by people. Subsequently, socially just resilience needs to acknowledge that communities can be heterogeneous and exhibit diverse needs, capacities, and levels of power. This is especially true when looking at historic areas and heritage whose values and functions need to be accessible to all members of society as an important building block for location-based identity and social cohesion. In addition, the resilience of historic areas needs to acknowledge the specific characteristics of these areas and recognize the need to balance socially just response and adaptation with the need to maintain the historic area's identity, integrity, and authenticity. The ARCH project therefore adapts the IPCC's resilience definition to address these issues and understands resilience as "The sustained ability of a historic area as a social-ecological system (including its social, cultural, 
political, economic, natural and environmental dimensions) to cope with hazardous events by responding and adapting in socially just ways that maintain the historic area's functions and heritage significance (including identity, integrity, and authenticity)" [23].

Although the resilience of cities has already been addressed in the general narrative around climate change, as well as in research [24], the increased variety of hazards that cities are currently tackling has brought it into greater focus [25]. City stakeholders, especially citizens, see the urgency of taking measures to enhance climate resilience. However, while some structured methods and tools for engaging city partners exist [26], the involvement of these stakeholders in research projects that develop resilience-enhancing tools has been challenging. For this reason, the European Commission has been requiring the integration of stakeholder engagement in research projects for several years in order to increase the impact of projects [27], using standardization as a tool to actively support exploitation and dissemination $[28,29]$.

The current standardization landscape provides some standards related to climate change adaptation or city resilience: for example, ISO 14090 "Adaptation to climate change-Principles, requirements and guidelines" and the ISO 37000 series on "Sustainable cities and communities" from the International Organization for Standardization (ISO). However, these are not in line with the specific cultural heritage-sensitive needs of historic areas as they are integrated into resilience planning. Furthermore, the traditional standardization system, based on technical committees, provides limited possibilities to directly transfer research project results into standardization. To meet this need, workshop agreements, such as the CEN (European Committee for Standardization) Workshop Agreements (CWA), are an appropriate instrument for resilience-related projects supporting the enhancement of resilience tools and the gathering of relevant stakeholders [30]. This type of agreement is suitable because it is developed in an open and temporary workshop environment and thus enables fast and easy engagement of project-external stakeholders.

Combining standardization with approaches like co-creation activities has only been used in a few projects to enhance research tools and to make them more usable for relevant stakeholders [31]. However, due to these limited cases and information available in the literature, it remains under-examined how the process for transferring a tool from a research project on (city) resilience into a standard can be conducted with the respective engagement of relevant stakeholders. Therefore, this research addresses two questions: how to adapt and validate a resilience-enhancing research tool for historic areas through standardization and how to engage project-internal and -external stakeholders during the development of a standard.

To respond to these questions, this paper analyses the ARCH (Advancing Resilience of Historic Areas Against Climate-Related and Other Hazards) project as a case study to validate existing approaches for integrating standardization in a resilience-related research project and to present the process for transferring a specific result of the project into a standard. The objective of $\mathrm{ARCH}$ is to make areas of cultural and historic value more resilient to climate-related risks and natural hazards [32]. Co-creation and standardization activities are being implemented in the project to adapt, verify, and enhance developed resilience tools for historic areas. This process involves, i.e., the four project cities and other external cities.

The paper is organized as follows: Section 2 further introduces the topic of resilience of historic areas and reviews approaches for using standardization in projects on city resilience. The methodology used for this research is described in Section 3. The findings of the research within the ARCH case study are presented in Section 4. Section 5 discusses the results obtained, and Section 6 highlights the main conclusions drawn from this research and provides an outlook for further research. 


\section{Review of Resilience Approaches}

\subsection{Approaches for Climate Change-Related Resilience of Historic Areas}

Several guidance documents and frameworks on CCA and DRM exist, which consider historic areas to different extents. For example, the United Nations Educational, Scientific, and Cultural Organization (UNESCO) handbook on Managing Disaster Risk for World Heritage provides a multiple-step approach for managers and administrators of heritage properties to support the implementation of the World Heritage Convention. Their methodology targets the identification, assessment, and mitigation of disaster risks for heritage sites and proposes a DRM cycle to raise awareness of potential risks faced by heritage sites. In addition, the handbook raises awareness of the potentially positive role of heritage sites in reducing disaster risks, as these sites provide services to the community ecosystem of which they are a part, and their specific properties, which are based on centuries of knowledge, have proven to be resilient [33].

The operational knowledge framework of the EU Horizon 2020 project SHELTER "Sustainable Historic Environments holistic reconstruction through Technological Enhancement and community-based Resilience" is another approach for the concept of resilience in cultural heritage targeting, i.e., local authorities, urban planners, and cultural heritage owners. The framework includes a CCA cycle that, during a disaster, moves from the pre-disaster phase to the post-disaster phase, in which the reconstruction takes place. After the reconstruction of the historic area, it moves back to its original position [34].

Another approach related to the reconstruction and recovery phase is the Culture in City Reconstruction and Recovery (CURE) Framework, developed by UNESCO and the World Bank [35]. The CURE Framework has seven guiding principles, starting from acknowledging the city as a 'cultural construct', through, i.e., people-centered and placebased strategies such as reconstructing places with relevance for the local community, to the balancing of addressing the needs of the people and recovering the historical character of the city. In order to implement the CURE Framework, four phases are suggested, including assessing and scoping the damage and needs, designing respective policies and strategies, identifying financial modalities for the reconstruction, and implementing the strategies.

Since 1966, the International Council on Monuments and Sites (ICOMOS) has already been working towards the conservation and protection of cultural heritage. Their Climate Change and Cultural Heritage Working Group prepared the report 'The Future of Our Pasts: Engaging Cultural Heritage in Climate Action', which highlights the impacts of climate change drivers on the main cultural heritage categories. They argue that cultural heritage serves as a source of resilience, i.e., for community resilience [36].

The ARCH project has built on existing approaches such as from ICOMOS in its publication "Good Practices in Building Cultural Heritage Resilience". This document outlines both tangible and intangible heritage assets and classifies cultural heritage into different types: movable heritage, archaeological resources, buildings and structures, cultural landscapes, associated and traditional communities, and intangible heritage [37]. The publication goes on to detail classifications of 40 cultural heritage resilience-enhancing initiatives and projects and outlines their ease of replicability/transferability to other communities. Aimed at an audience of public administrators, policy makers, and municipal employees, the publication guides readers through various approaches that might inspire action in communities in which historic areas face natural and climate-related hazards. In addition, the report provides eight case studies in more detail that explore challenges and lessons learned from integrated resilience building processes for historic areas. The case studies were based on semi-structured interviews that were conducted with stakeholders closely involved in each case.

In both DRM and CCA, it is necessary to model proposed decision support processes and their embedding in or relation to other processes. In this way, stakeholders are encouraged to make optimal use of limited available resources to achieve the highest possible level of resilience maturity. Decision support developed for and used in the 
complex task of CCA and DRM can be roughly divided into the following categories of action:

(1) Assessment—vulnerability and risk assessment.

(2) Reporting and presenting results at the political level.

(3) Planning, implementing, and monitoring adaptation measures.

In recent years, work has been published on frameworks for describing city resilience and has suggested tools for improving city resilience, emphasizing the importance of stakeholder engagement and interaction for city resilience [38-40].

\subsection{Standardization in Research Projects on Climate Change-Related (City) Resilience}

Only a few research projects on (city) resilience exist with any useful level of integration of standardization. Furthermore, the literature provides very limited information as to how this integration happened in those few cases, and it does not expound upon how relevant stakeholders have been successfully engaged in order to transfer the resilience tools into their practice [41]. However, several European research projects emphasized (city) resilience to climate change effects and included standardization to different extents [41]. Nevertheless, in most cases, these proceeded differently due to a missing common approach and lack of experience with standardization, and only a few of them directly address historic areas.

One example, besides the ARCH project (see Section 4.1), is the project STORM, which aimed to develop tools for cultural heritage stakeholders to support the prevention, response, and recovery phase of securing cultural and historic sites. STORM analyzed existing standards, such as the Common Alerting Protocol included in ITU-T X.1303, and identified gaps in standardization, including a proposal for a data standard for the different types of cultural heritage assets and a required promotion campaign [42].

Another related initiative, the Italian research project "Built Environment Safer in Slow and Emergency Conditions through behavior Ural assessed / designed Resilient solutions" (BE S ${ }^{2} E S U R e$ ) focusses on the human-made environment, also called the built environment (BE), to which historic areas belong. BE $S^{2} E C U R e$ aims at developing methods, tools, and guidelines to assess the resilience of the $\mathrm{BE}$ and to increase the resilience and safety of the $\mathrm{BE}$ and its users. Several standards were considered in the development of the solutions, and the yet to be developed guideline on resilience strategies for $\mathrm{BE}$ is an approach to be considered in the future [43,44].

Another example that is not directly targeted toward historic areas is the Smart Mature Resilience (SMR) project, which aimed to develop a European Resilience Management Guideline that integrated five resilience-enhancing tools, but also considered critical infrastructure dependencies and societal aspects. In addition, the project incorporated standardization throughout its implementation and used a co-creation method to involve further cities and their stakeholders simultaneously in tool development, testing, and validation [45]. The standardization process resulted in the CWA 17300 standards series on 'City Resilience Development', developed among others by the seven project cities and another six cities and city associations [46]. The series consists of the following three CWAs: CWA 17300 City Resilience Development—Operational Guidance; CWA 17301 City Resilience Development-Maturity Model; and CWA 17302 City Resilience DevelopmentInformation Portal. The CWA on Operational Guidance is the overarching document that refers to CWA 17301 City Resilience Development-Maturity Model, CWA 17302 City Resilience Development-Information Portal, and other supporting tools.

Furthermore, the RESIN project compared and evaluated methods used for climate change adaptation planning and provided suggestions for the inclusion of strategizing options for adaptation into formal standardization activities. While standardization was originally envisaged as a crosscutting exercise spanning all four city cases of the project, it was not consistently implemented in all co-creation activities. Instead, standardization was pursued from the viewpoint of technical partners developing tools and methods and a subsequent transfer of results into international standardization committees [47]. 
However, the literature on cases such as those mentioned above is very limited. Additionally, these project examples show, on the one hand, the lack of a common approach to the integration of standardization and, on the other hand, the different levels of knowledge about standardization and how it can be successfully implemented as a tool within research activities. However, a recent study on resilience-related research projects concluded with the proposal to consider five steps aimed at integrating standardization, including analysis of existing standards, identifying end-user needs and standardization gaps, developing a standardization strategy, initiating end-user focused standardization activities, and promoting and further exploiting the standardization results [41]. The initiation of standardization activities in European projects mostly led to the development of CWAs [48]. The steps to develop a CWA provide several possibilities to foster engagement with relevant stakeholders, e.g., public availability and commenting possibilities that are a part of the CEN Workshop project plan; the possibility to join CEN Workshops, which are ongoing at any given time; or the opportunity to partake in optional commenting phases of draft standards. Due to the relation of the envisaged standard to a tool or method developed in the project, the CEN Workshop process can also be combined directly with co-creation activities of envisaged project outcomes.

Although standardization in the field of (city) resilience has been recently identified as a gap, and therefore a research priority $[49,50]$, research projects often do not have an explicit focus on the resilience of historic areas. In addition, existing literature is lacking information on the process of transferring a resilience-enhancing tool for historic areas linked with co-creation activities into the content of a standard. The presented research overcomes this gap and provides details on how the relevant stakeholders are engaged with the support of co-creation activities.

\section{Methodology}

In order to respond to the research questions on how to adapt and validate a resilienceenhancing research tool for historic areas through standardization and how to engage project-internal and external stakeholders during the development of a standard, the action research methodology was used [51]. Chein et al. [52] proposed four dimensions for action research: diagnostic, empirical, experimental, and participatory. For participatory action research, the authors describe it as a method in which researchers and practitioners actively take part in all research stages. This method has proven to make scientific results useful for practitioners [53]. As previously stated, the literature is very limited for cases that detail how standardization is integrated into research projects. Thus, the participatory action research methodology has been chosen due to the direct involvement of the researchers in a specific project and thus will support providing detailed insights of research currently ongoing.

The method of combining standardization with co-creation activities can be an appropriate tool to improve and validate tools developed in research projects. Co-creating the inputs and outputs of research activities translates the "research-based" outcomes into more practical or "market-oriented" outcomes, as is shown in an example of a study with the public and governments [54]. Participatory research methods, including co-creation, benefit from their facilitation of interaction among relevant stakeholders, their transfer of the scientific process closer to decision makers, and thus the improvement of the perception of research outcomes [55].

For topics such as (city) resilience, there is especially a high need for bringing resilienceenhancing tools to market quickly, as risks increase due to the effects of climate change and natural hazards, among other causes. Combining standardization with co-creation activities provides a win-win approach for researchers who will bring their tools to market and for practitioners who directly influence tool development with their essential inputs.

With regard to fostering stakeholder interaction in city-related projects, it is crucial to use acknowledged processes to identify and prioritize relevant stakeholders: for example, 
by considering the projects' team experiences and structuring the relations among all relevant stakeholders [56].

In summary, the participatory action research methodology will support gathering information of ongoing projects related to resilience with standardization, thus filling the gap in the existing literature as well as in the standardization landscape. The different activities of the research conducted are presented in Figure 1.

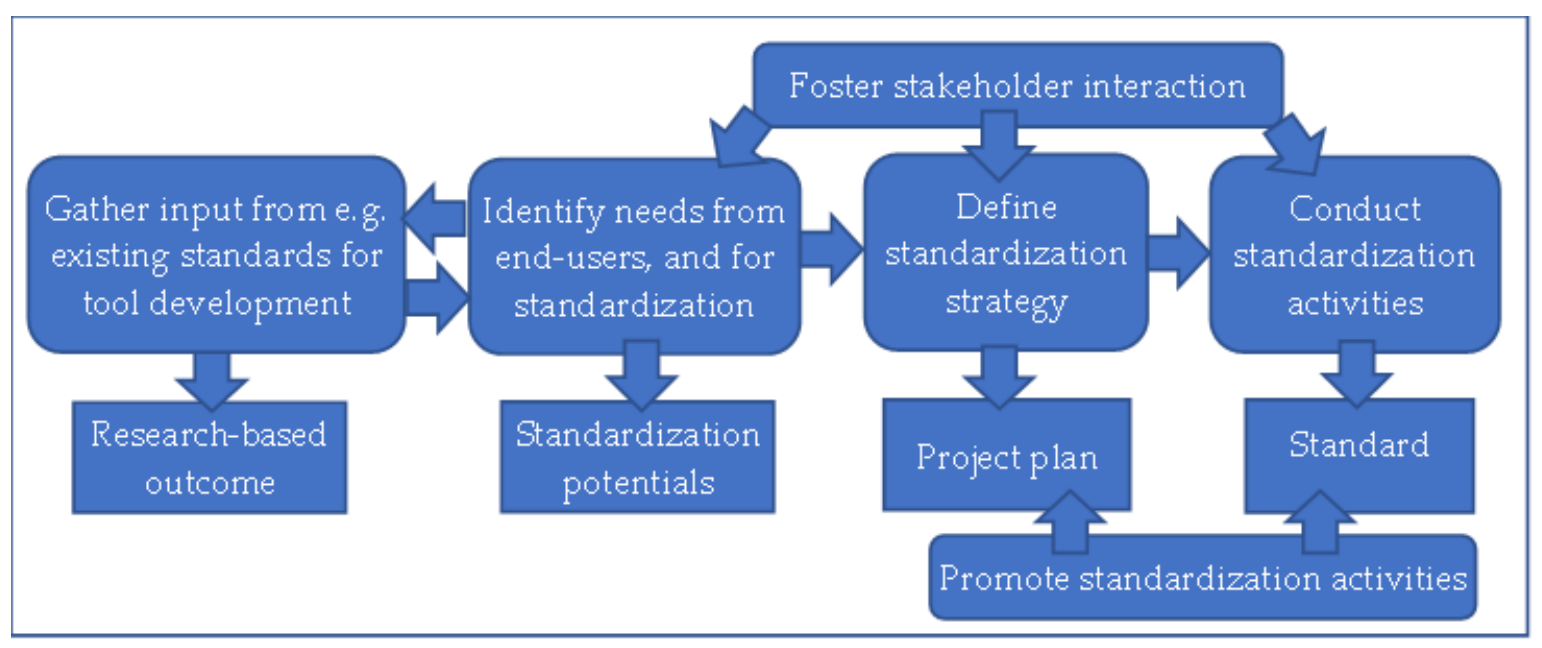

Figure 1. Methodology of the research (based on the 5 steps of Lindner et al. [41]).

At first and within the first half year of a research project, the tool development is supported by assessing relevant projects, literature, standards, and further initiatives and considering of the needs of (project-internal) stakeholders. This leads to the development of the "research-based" outcome (the report on the tool for the funding agency and/or the public). Afterwards, the standardization potential of the project tool(s) within the existing standardization landscape is analyzed, taking into account the results of the previous step. After having identified these potentials, approximately halfway through the project, a strategy on how to address them is developed, including a prioritization of the standardization potentials and possible channels through which to transfer them into standardization. As previously mentioned, a workshop agreement is one tool to develop a standard out of a research project. This requires the development of a standardization project plan before starting and thus is a possible outcome of the standardization strategy. Finally, the development of the standard takes place, in which the project tool content is adapted as a "market-oriented" outcome with the support of a wider range of stakeholders. Therefore, the relevant stakeholders need to be identified and prioritized beforehand. These project-external stakeholders validate and adapt the tool content for the standard together with the project partners, thus effectively implementing co-creation in the standardization process. The process of a workshop agreement supports this, as it offers with its flexible and open process environment several possibilities to engage with relevant stakeholders. Furthermore, the standardization activities, starting with the project plan and ending with the availability of the developed standard, are promoted to a wide range of stakeholders and within the standardization system itself. The development of a workshop agreement has a duration of approximately 8 to 12 months and is usually conducted in the last year of the project.

The outcomes of this research will support the validation of approaches to integrating standardization in research projects. This will result in stronger stakeholder engagement in tool development and a more successful exploitation of co-creation and standardization activities. 


\section{Results}

The EU-Horizon 2020 project ARCH was analyzed through the direct participation of the researchers in the project or, more specifically, within the project-initiated standardization activities. All steps of the methodology described in Section 3 can be revised within this project.

\subsection{Standardization and Co-Creation within the ARCH Project}

The project's aim is to provide tools to make historic areas more resilient against risks related to climate change and natural hazards. Therefore, it collects existing and new information about hazards and vulnerabilities, assesses risks and resilience of historic areas considering different scenarios, and identifies possible ways and action plans to increase the resilience of historic areas. In order to develop, validate, and adapt the project tools, co-creation and standardization activities are implemented, consisting of co-creation workshops called "mutual learning activities", or the "Mutual Learning Framework". The development of standards is undertaken in alignment with this process.

$\mathrm{ARCH}$ is a city-focused project including partners from the cities of Bratislava, Camerino, Hamburg, and Valencia, who support the co-creation of the tools in order to help to protect the historic areas of their respective cities and other cities from the effects of climate change and natural hazards. Within the mutual learning activities, besides the four project cities (Foundation cities), another twelve European cities (Keystone cities) are involved to foster knowledge and experience exchange. The Keystone cities take part in this in order to learn from the testing activities in the project partner cities and therefore increase the resilience of their own historic areas [32]. Figure 2 provides an overview of the cities involved.

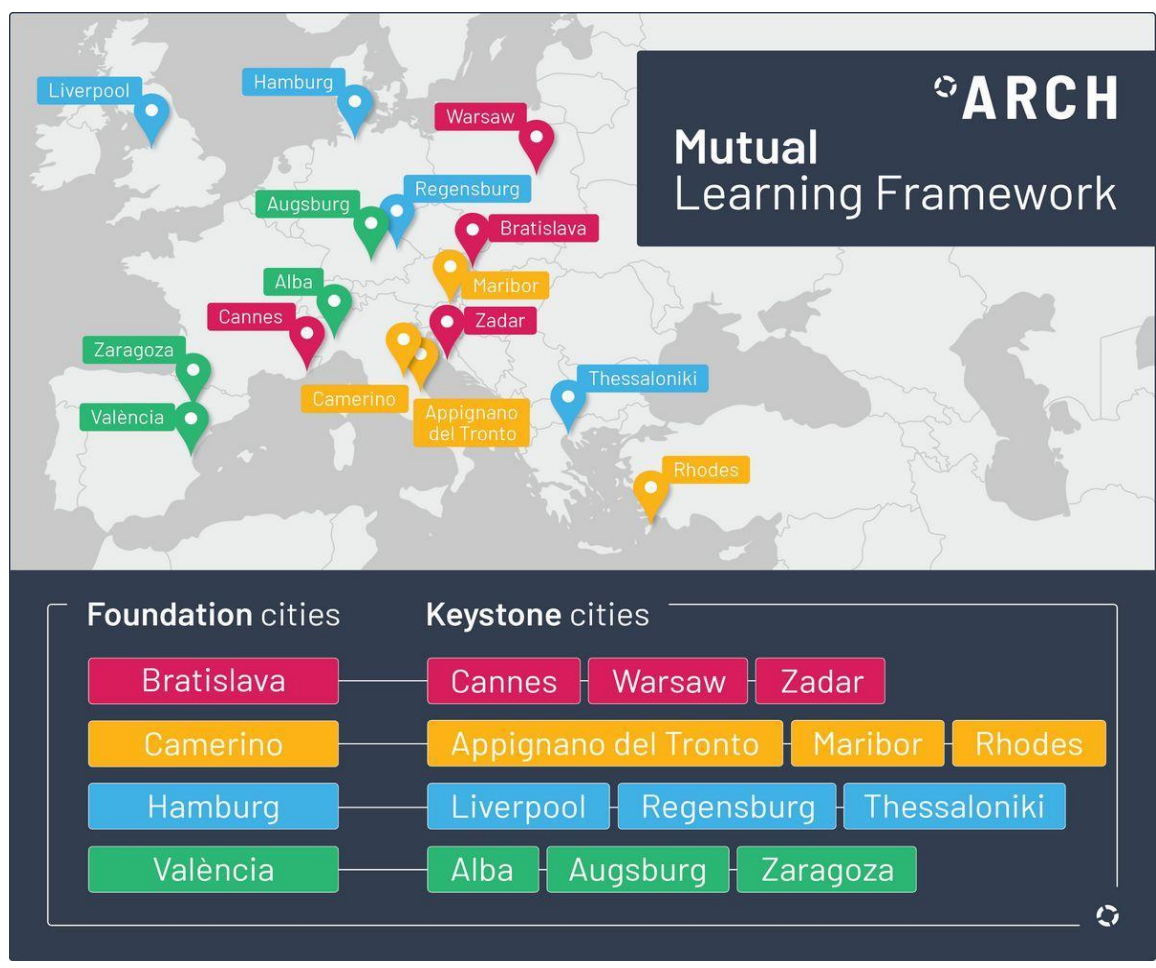

Figure 2. Overview of cities involved in the ARCH mutual learning activities [32].

The ARCH co-creation method follows criteria, such as equality, flexibility, openness, inclusiveness, reflexive or iterative learning, and transparency, as well as accountability, credibility and trust, which are all described in the project's co-creation framework in detail [57]. These are well aligned and complement some of the principles of standardization work, namely those that refer to its voluntary nature, openness, broad participation, 
need for consensus, uniformity and consistency, international relevance, and need for high acceptance [58].

ARCH integrates standardization into the full length of the project. Initially, an assessment of existing standards relevant to the different project tools was conducted, supporting the development of these tools and their compliance to existing standards and regulations. Afterwards, the standardization potentials of the project outcomes were evaluated based upon the identification of needs of the cities and for standardization, following a strategy and project plan for initiating standardization activities.

\subsection{DRM Framework Development Considering Standards}

The ARCH DRM Framework is one of the principal outputs of the $\mathrm{ARCH}$ project and was developed in a collaborative environment, using feedback from project partners over the course of multiple discussions and feedback rounds [23]. Project partners were engaged in in-depth interviews in order to ascertain which requirements would guide the framework based on existing standards and previous research projects. The compilation of additional requirements also formed the basis of a "match-making" meeting between city partners and technical partners involved in $\mathrm{ARCH}$. During these meetings, locally specific challenges faced in ARCH cities were matched with the specific expertise of technical partners. The results of this process did not elicit many existing standards, likely a result of the new and innovative approaches employed by ARCH in combining CCA and DRM. Nonetheless, the CWA 17300 series on "City Resilience Development" was identified as the most relevant. Overall, the ARCH DRM Framework was composed as a direct outcome of these various collaborative efforts, in addition to the review of existing frameworks, guidelines, and models. However, the process is neither formally nor informally closed; additional feedback is welcomed over the remainder of the project.

As displayed in Figure 3, the ARCH DRM Framework brings together DRM and CCA in the context of historic areas. Specifically, the DRM and CCA cycles are brought together into an integrated paradigm, which lends particular attention to the context of historic areas. Reconstruction-related concepts include that of "Building Back Better" [59], which aims to help rebuild the resilience of historic areas in a way that transcends their pre-disaster state. The framework includes ten steps divided between "pre-disaster", "during", and "post-disaster" phases. These steps are intended to be adapted to the unique context of a local situation or specific disaster and are meant to be understood as consecutive but not necessarily entirely separate from one another.

The ARCH DRM Framework goes further to split all of the aforementioned steps into "normal operating" phase (the pre-disaster phase) and the "emergency operation" phase (namely, the during and post-disaster phases), as denoted by the outermost light and dark gray rings in Figure 3. As long as no disaster occurs, the steps in the "normal operating" phase are repeated, skipping from Step 6 to Step 1 (bypassing 7-10). These first six steps mirror the adaptation planning cycle of the Urban Adaptation Support Tool (UAST) [60], but are expanded upon with the necessities for disaster preparation.

The ARCH DRM Framework makes the case for carrying out vulnerability and risk assessments for not only sudden-onset but also slow-onset climatic risks. It encourages not only the identification and implementation of CCA measures, but also risk prevention and mitigation as well as emergency response measures. What sets the ARCH DRM Framework apart from the usual DRM cycle is best exemplified in Step 6, where in lieu of conducting a review between the post- and pre-disaster phases, $\mathrm{ARCH}$ follows the CCA cycle and advocates for the establishment of a monitoring, evaluation, and learning framework [61] as the final step of the pre-disaster phase (with a revision of this framework and process as part of Step 10 in the case of a disaster).

This framework, which encompasses monitoring, evaluation, and learning, is not meant only to manifest in implementation efforts, but also in monitoring the combined DRM and CCA process in and of itself, in order to adjust and allow for iterative and appropriate change. 


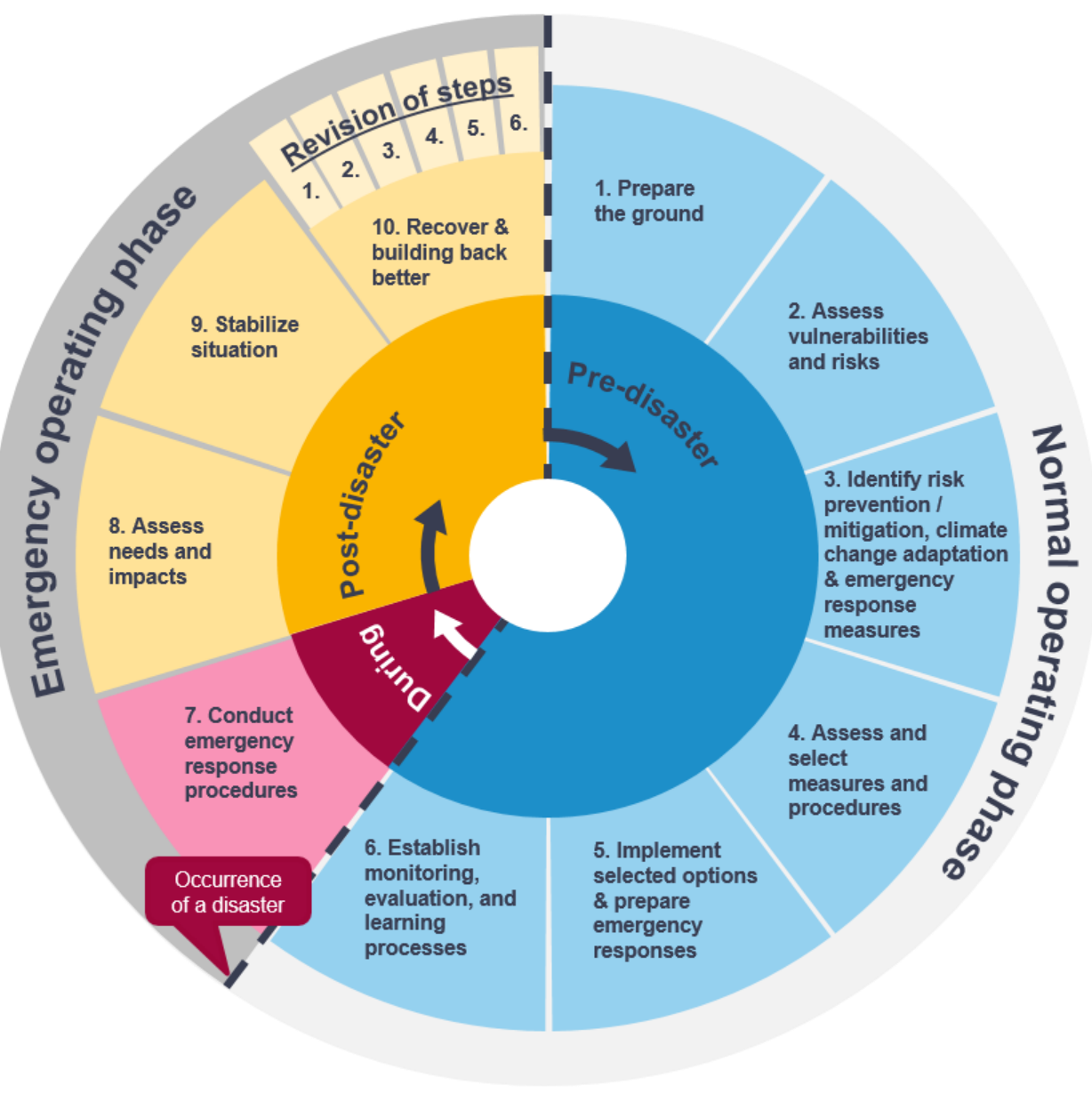

Figure 3. Illustration of the ARCH DRM Framework [23].

Meanwhile, in the case of the occurrence of a disaster, the "normal operating phase" shown in the light gray outer circle in Figure 3 is disrupted, and leaves the door open for the implementation of Steps 7 through 10. These are focused on emergency response and post-disaster recovery, but are highly dependent on the preparations undertaken in Steps 1 through 6. This phase, the "emergency operating phase", also has space for a revision of the results of the "normal operating phase", as denoted in Step 10. This encourages adjustments and additions of new information that may only come from the lived experience of dealing with disaster response and recovery. Likewise, Steps 1 through 6 are clearly geared towards the "emergency operating phase", and any post-disaster responses should be used as an opportunity to review (CCA) measures and to advance the goals of "Building Back Better".

The ARCH DRM Framework is, for the above reasons, to be seen and used as a DRM cycle that includes two conditionally interlinked CCA cycles (see Figure 3): one that is conducted and repeated in the "normal operating phase" before the presence of a disaster situation and another that informs the ways communities respond to and rebuild after disasters (as part of Step 10) [23].

\subsection{Standardization Strategy of ARCH}

As the next standardization-related activity in $\mathrm{ARCH}$, a strategy for the projects' standardization activities was developed. In this process, the needs for standardization within the project were identified by assessing the project results for their readiness to be transferred into standards and/or for their possible use as input to already existing standards.

The challenges and needs, for which standardization might be a solution, were collected from the project cities and further research partners. In total, 33 representatives of the 
project partners and the advisory board (in total, 20 from research and 13 from cities/city network) took part in a standardization potential workshop and identified 18 challenges or needs that were divided into the following topics: terminology, indicators and measures, warning systems and strategy, and operations. A follow-up workshop with the project partners summarized the input based on the gaps in existing standards, the needs identified, and the tools developed in the project and identified in total five standardization potentials on:

1. Definition of terms and definitions for the resilience of historic areas.

2. The resilience building of historic areas in cities and communities, including characterization of historic areas, indicators for resilience assessment, and processes to manage and monitor resilience building.

3. The impacts of damages on historic areas caused by climate change-related hazards, including existing heritage metadata of descriptors for risk assessment.

4. How to develop, implement, and maintain an alert system for historic areas.

5. Involvement of people and organizations in research projects that are not familiar with such projects: e.g., a guideline on how to create a mutually beneficial partnership.

Afterwards, four project partners (from research and the city network) that are highly involved in the task rated the standardization potentials using the following criteria: feasibility, transferability, ability to fill a gap, need for the document, and required input from project external partners. The same evaluation criteria were successfully used in the previously presented SMR project [41]. The maximum score was 5, which could be achieved by rating each criterion with a yes (which counted as 1 point, and a neutral ranking was counted as 0.5 points). The second standardization potential identified above was evaluated as the best and was suggested to be transferred into a new standardization activity titled "Disaster Risk Management Framework-Implementation on historic areas". All other project partners were consulted on the ratings and approved the decision. Table 1 summarizes the assessment. The results of the standardization potential task have been shared in a small session with projects funded by the same call, in order to find similarities for the future standardization activities and to obtain commitments of support.

Table 1. Overview of assessment of identified standardization potentials.

\begin{tabular}{|c|c|c|c|c|c|c|}
\hline $\begin{array}{c}\text { Criteria/Standardization } \\
\text { Potential }\end{array}$ & Feasibility & Transferability & $\begin{array}{l}\text { Filling a } \\
\text { Gap }\end{array}$ & $\begin{array}{l}\text { Need for the } \\
\text { Document }\end{array}$ & $\begin{array}{l}\text { Input from } \\
\text { Externals } \\
\text { Needed }\end{array}$ & $\begin{array}{l}\text { Score in } \\
\text { Points }\end{array}$ \\
\hline 1 & No & Yes & Neutral & No & Yes & 2.5 \\
\hline 2 & Yes & Yes & Yes & Yes & Yes & 5 \\
\hline 3 & Neutral & No & Neutral & Neutral & Yes & 2.5 \\
\hline 4 & No & Yes & No & Yes & Yes & 3 \\
\hline 5 & No & No & No & Neutral & Yes & 1.5 \\
\hline
\end{tabular}

(Legend: Yes $=1$ point; Neutral (equal amount of yes $/$ no) $=0.5$ points; No $=0$ points).

As no other standardization activity related to the chosen project tool existed, a CEN Workshop, which is a fast-track standardization option, was suggested to transfer the project tool into a standard. The respective project plan for this CEN Workshop was developed and made publicly available online for commenting for 30 days. One year was determined as the proposed duration of the standardization activity. The following section provides detailed information on the standard's development.

To conclude the standardization strategy and to support the standardization activities in $\mathrm{ARCH}$, the project foresees the setup and appointment of a liaison with relevant standardization committee(s) of CEN or ISO to ensure the uptake of the standardization outcomes of the project directly within these committees as, for example, an ISO standard. 


\subsection{Developing a Standard on the DRM Framework by Including Co-Creation Activities}

The CEN Workshop, the outcome of which will be the CWA 17727, was constituted during a standardization kick-off meeting in May 2021 [62]. In total, 59 participants took part in this meeting. Ultimately, 42 people approved the project plan and are therefore members of a temporary working group called "CEN Workshop ARCH". It is notable that only one third of the CEN Workshop members are working within $\mathrm{ARCH} ; 5$ people are from SHELTER, the sister project of ARCH funded under the same call; and the other 23 people are from other cities, ministries, research institutions, consultancies, standardization bodies, industries, and NGOs (such as from the ARCH Mutual Learning Framework). This demonstrates the wide-reaching interest in such activities and the support for the development of standards through projects such as ARCH. To develop the CWA 17727, the CEN Workshop members as well as Mutual Learning Framework participants are engaged using mainly online workshops and digital collaboration tools. As the number of participants in the CEN Workshop is relatively high, a core group consisting of five people coming from ARCH and one person from the SHELTER project has been established to guide the standard development and to prepare the interaction with the other CEN Workshop members.

A standard, such as the envisaged CWA, includes different chapters, starting from the introduction, which sets the scene on the topic, and continuing with the scope, a section explaining the aim and target group of the document. The standard also includes relevant terms and definitions, a general description of historic areas, and the 10 phases included in this framework. Additionally, a European foreword is provided in which the contributors to the standard are listed. Furthermore, the sections describing the content of the standard are foreseen to be more requirements than recommendations, thus giving the applier of the document a stronger obligation to follow. As the Terms and Definitions section provides relevant terminologies for the resilience of historic areas, another previously identified standardization potential is also partly answered in the CWA.

The first three meetings of the CEN Workshop focused on the characterization of historic areas and the transfer of the first three steps of the ARCH DRM Framework. The rather research-based output of the ARCH project [23] has been shifted to a more market-oriented output. Thus, the content of the original ARCH DRM Framework has been transferred into the CWA by, at first, providing general information on the steps, requirements for the successful completion of each step, additional recommendations and indicators, and supporting materials and tools. The core group initially provided proposals for these subsections, based on the ARCH DRM Framework, and have validated, enhanced, and complemented them for the first three steps in three meetings of the CEN Workshop that involved all members.

The aim of the CWA, therefore, is to further develop, together with a broader community of experts including municipal staff, the ARCH DRM Framework and to help practitioners, decision makers, heritage managers, public administrators, and other actors in the field of DRM, CCA, and historic area management: (1) to acknowledge the need for socially just resilience building activities; (2) to understand which steps are necessary to develop a Resilience Action Plan, which combines both processes (DRM and CCA) and takes needs and opportunities of historic areas into account when building resilience; (3) to provide guidance on how to operationalize the different steps of the ARCH DRM Framework; (4) to provide guidance on which stakeholders to involve in each step of the ARCH DRM Framework; and (5) to provide a conceptual structure for the use of different supporting tools and materials within the steps of the ARCH DRM Framework.

To that end, the input was distributed one week in advance to the CEN Workshop members using the digital brainstorming tool Miro, in which each member had the chance to provide information before the meetings. Within the meetings, the contributions were refined, complemented, and directly discussed. Different facilitation methods, such as a world café [63], were used to ensure constructive interaction among more than 40 
CEN Workshop members. The results of the workshops are directly transferred into the draft CWA.

Through the different ways of engaging the stakeholders, the first three steps of the ARCH DRM Framework could be significantly advanced, especially with projectexternal views. In the next months, the other seven steps will be similarly validated and complemented and undergo an optional commenting phase with the involvement of the public. Standardization workshops within the Mutual Learning Framework of ARCH will be conducted to include the view of further stakeholders. Furthermore, promotional activities are planned to provide information on the standardization activities and thus gather support for the potential future uptake of the CWA as, for example, a potential ISO standard.

\section{Discussion of the Results}

This research aimed to assess the possibilities of standardization to adapt and validate a resilience-enhancing research tool for historic areas, as well as to foster engagement with project-internal and external stakeholders. The assessment of the $\mathrm{ARCH}$ project activities shows the progress in developing a standard to foster the transfer of a research result, the ARCH DRM Framework, into practice.

The assessment of relevant standards for the project has contributed to the development of the DRM Framework. This allowed for the consideration of requirements of existing standards in the DRM Framework as well as the early identification of its potential for the purposes of standardization. This confirms the state-of-the-art character of standards that should be taken into account when assessing inputs for projects such as ARCH. However, one caveat might be that existing standards can also limit the researcher in the tool development, as they might be seen as potential guardrails that need to be followed.

However, in this case, the usage of already-applied evaluation criteria made the standardization potential assessment more credible and faster and confirmed, at the same time, approaches used in previous projects [41]. Nevertheless, the identification of the project's standardization potential depended mostly on the view of project-internal stakeholders. However, through the initiation of the standard and the development of the project plan, experts from standardization committees evaluated and supported the standardization process. This, along with the active promotion of the project plan, finally led to the involvement of a variety of stakeholders, such as other cities and standardization bodies, which again confirms other existing approaches [31]. As two thirds of the CEN Workshop members are not from the ARCH project, achieving consensus might be more difficult and project-specific content-related discussions might distract from the overall goal of the standard. Due to the large number of people involved and the potential risk of inattention, the process for progressing on the standard's development may slow down after its initial momentum. In light of the fact that due to COVID-19 restrictions, physical meetings could not be held, the conducting of online meetings brought up advantages such as faster input gathering but also disadvantages such as a lack of networking insights that happen more readily in face-to-face meetings. The pure use of digital tools is not enough, as an active request for input is needed to obtain the involvement and commitment of the CEN Workshop members. Therefore, more interactive methods such as world café facilitation approaches have been recognized as crucial.

In summary, the five steps suggested in the previous literature [41] can already be partly confirmed with this research. However, as the ARCH project, along with its standardization activities, has not been finalized, the general benefits of the involvement of the stakeholders remain (at least in part) to be seen. The results should be reviewed once again and confirmed towards the end of the project. Even so, it can already be stated that through the standardization and co-creation activities, the initial ARCH DRM Framework has been enhanced with the input provided by the stakeholders included. Standardization activities provided the possibility to adapt the project result according to the needs of the 
involved stakeholders while providing those same stakeholders with some kind of training on resilience-enhancing tools for historic areas.

The limitations of this research include the ongoing process of the ARCH standardization activities, which have so far provided information for the envisaged standard only on the first three steps of the DRM Framework. Furthermore, the focus of this research is only set in a very specific field. However, as identified in Section 2, other cases are rare, and thus insights such as those from $\mathrm{ARCH}$ provide the basis for further research.

\section{Conclusions}

The resilience of historic areas is a topic that may be underestimated and underexamined due to the different challenges society is facing, especially the visible and dramatic impacts of climate change on other parts of communities. The research conducted in the $\mathrm{ARCH}$ project validates already partly existing research on the integration of standardization in research projects and provides essential insights and resources to ensure the existence of cultural and historical sites for the next generations. ARCH has increased the efficacy of these outputs by considering existing standards to support the development of the respective methods and tools and transferring results via standardization into more user-friendly and acknowledged outcomes. All of this being done through the involvement of relevant stakeholders makes the integration of standardization in research projects highly beneficial—for the project and affected communities alike.

Although the literature on the integration of standardization in research projects is rare, the few existing studies could be confirmed with this examination of the standardization work conducted within the ARCH project. It has been shown that co-creation activities to develop a method or tool supporting the resilience of historic areas can be meaningfully supported when standardization activities are brought into the process. Researchers benefit from receiving more feedback by additional project external stakeholders to enhance their tools, and potential end-users have the possibility to actively influence tool development, creating resources that work for their own respective contexts.

It can be concluded that with the provision of the process of transferring a resilienceenhancing project tool into a standard as well as the related consideration of relevant stakeholders, the respective research questions can be answered, and the five steps proposed in the previous literature can already mostly be confirmed [41]. Furthermore, with the development of resilience-related standards, ARCH supports partly overcoming the gap identified by Zuccaro et al. [50]. However, as the project has not ended yet, further insights into and validation of the benefits are to be expected. Finally, the implications of this research can serve future research activities to provide more success cases of how standardization and co-creation can be integrated into research projects, whether they deal with city resilience or otherwise.

Author Contributions: Conceptualization, methodology, R.L., D.L. and C.J.; validation, investigation, resources, data curation, R.L., D.L., K.M., O.U., S.M., K.P., V.L., J.H. and C.J.; writing-original draft preparation, R.L. and O.U.; writing—review and editing, R.L., D.L., K.M., O.U., S.M., K.P., V.L., J.H. and C.J.; visualization, R.L., K.M. and O.U.; supervision, project administration, R.L. All authors have read and agreed to the published version of the manuscript.

Funding: This research within the ARCH project has received funding from the European Union's Horizon 2020 research and innovation programme under grant agreement number 820999 . The sole responsibility for the content of this publication lies with the authors. It does not necessarily represent the opinion of the European Union. Neither the REA nor the European Commission is responsible for any use that may be made of the information contained therein.

Institutional Review Board Statement: Not applicable.

Informed Consent Statement: Not applicable.

Data Availability Statement: The data presented in this study are available upon reasonable request from the corresponding author. 
Conflicts of Interest: The authors declare no conflict of interest.

\section{References}

1. European Commission. Europe's Cultural and Natural Heritage in Natura 2000; Publications Office of the European Union: Luxemburg, 2018. Available online: https:/ / ec.europa.eu/environment/nature/natura2000/management/pdf/Nature-andCulture-leaflet-web.pdf (accessed on 27 September 2021).

2. Nicol, S.; Roys, M.; Ormandy, D.; Ezratty, V. The Cost of Poor Housing in the European Union; University of Warwick: Coventry, UK, 2016. Available online: https://www.bre.co.uk/filelibrary/Briefing\%20papers/92993_BRE_Poor-Housing_in_-Europe.pdf (accessed on 27 September 2021).

3. European Commission. Overview of Natural and Man-Made Disaster Risks the European Union May Face; European Comission: Brussels, Belgium, 2021. Available online: https:/ / ec.europa.eu/echo/sites/default/files / overview_of_natural_and_man-made_ disaster_risks_the_european_union_may_face.pdf (accessed on 10 September 2021).

4. García-Soriano, D.; Quesada-Román, A.; Zamorano-Orozco, J. Geomorphological hazards susceptibility in high-density urban areas: A case study of Mexico City. J. South Am. Earth Sci. 2020, 102, 102667. [CrossRef]

5. Quesada-Román, A.; Villalobos-Portilla, E.; Campos-Durán, D. Hydrometeorological disasters in urban areas of Costa Rica, Central America. Environ. Hazards 2021, 20, 264-278. [CrossRef]

6. World Economic Forum. The Global Risks Report 2021, 16th ed. 2021. Available online: http://www3.weforum.org/docs/WEF_ The_Global_Risks_Report_2021.pdf (accessed on 10 September 2021).

7. ICOMOS. Resolutions of the General Assembly. In Proceedings of the 19th General Assembly of ICOMOS, New Delhi, India, 11-15 December 2017. Available online: https://www.icomos.org/images/DOCUMENTS/General_Assemblies/19th_Delhi_20 17/19th_GA_Outcomes/GA2017_Resolutions_EN_20180206finalcirc.pdf (accessed on 10 September 2021).

8. Bigio, A.G.; Ochoa, M.C.; Amirtahmasebi, R. Climate-Resilient, Climate-Friendly World Heritage Cities. In Urban Development Series Knowledge Papers; World Bank: Washington, DC, USA, 2014. Available online: https:/ /openknowledge.worldbank.org/ handle/10986/19288 (accessed on 10 September 2021).

9. Markham, A.; Osipova, E.; Lafrenz Samuels, K.; Caldas, A. World Heritage and Tourism in a Changing Climate; UNESCO Publishing: Paris, France, 2016. Available online: https:/ / whc.unesco.org/document/139944 (accessed on 13 September 2021).

10. Sesana, E.; Gagnon, A.S.; Bertolin, C.; Hughes, J. Adapting Cultural Heritage to Climate Change Risks: Perspectives of Cultural Heritage Experts in Europe. Geosciences 2018, 8, 305. [CrossRef]

11. GPDRR_Global Platform for Disaster Risk Reduction, Heritage and Resilience. Issues and Opportunities for Reducing Disaster Risks; UNESCO: Geneva, Switzerland, 2013. Available online: https://whc.unesco.org/document/122923 (accessed on 13 September 2021).

12. IPCC. Annex II: Glossary. In Climate Changing: Synthesis Report; Contribution of Working Groups I, II and III to the Fifth Assessment Report of the Intergovernmental Panel on Climate Change; Mach, K., Planton, S., von Stechow, C., Eds.; IPCC: Geneva, Switzerland, 2015.

13. United Nations. Sendai Framework for Disaster Risk Reduction 2015-2030. 2015. Available online: https://www.preventionweb. net/files/resolutions/N1516716.pdf (accessed on 1 November 2021).

14. United Nations. Paris Agreement on Framework Convention on Climate Change. 2016. Available online: http://unfccc.int/ resource/docs/2015/cop21/eng/10a01.pdf (accessed on 1 November 2021).

15. United Nations. Website on Sustainable Development Goals. 2021. Available online: https://www.un.org/sustainabledevelopment/ sustainable-development-goals / (accessed on 1 November 2021).

16. The Rockefeller Foundation. Website on 100 Resilient Cities. 2021. Available online: https://www.rockefellerfoundation.org/10 0-resilient-cities / (accessed on 1 November 2021).

17. Resilient Cities Network. Website. 2021. Available online: https://resilientcitiesnetwork.org/ (accessed on 1 November 2021).

18. UNDRR. Website on Disaster Resilience Scorecard for Cities. 2017. Available online: https://www.unisdr.org/campaign/ resilientcities/toolkit/article/disaster-resilience-scorecard-for-cities.html (accessed on 1 November 2021).

19. Alexander, D. Resilience and disaster risk reduction: An etymological journey. Nat. Hazards Erath Syst. Sci. 2013, 13, $2707-2716$. [CrossRef]

20. Nielsen, L.; Faber, M. Impacts of sustainability and resilience research on risk governance, management and education. Sustain. Resilient Infrastruct. 2019, 6, 1-46. [CrossRef]

21. Seelinger, L.; Turok, I. Towards Sustainable Cities: Extending Resilience with Insights from Vulnerability and Transition Theory. Sustainability 2013, 5, 2108-2128. [CrossRef]

22. Holling, C. Engineering Resilience versus Ecological Resilience. In Engineering within Ecological Constraints; Schulze, P., Ed.; National Academy Press: Washington, DC, USA, 1996; pp. 31-44.

23. Milde, K.; Lückerath, D.; Ullrich, O. ARCH Disaster Risk Management Framework. EU H2020 ARCH (GA No. 820,999), Deliverable D7.3. 2020. Available online: https://savingculturalheritage.eu/fileadmin/user_upload/Deliverables/ARCH_D7.3 Disaster_Risk_Management_Framework_v20201130-FINAL.pdf (accessed on 21 September 2021).

24. Rockefeller Foundation; ARUP. City Resilience Framework; Ove Arup \& Partners International Limited: London, UK, 2014. Available online: https://www.rockefellerfoundation.org/wp-content/uploads/City-Resilience-Framework-2015.pdf (accessed on 15 September 2021). 
25. McCartney, G.; Pinto, J.; Matthew, L. City resilience and recovery from COVID-19: The case of Macao. Cities 2021, 112, 103130. [CrossRef]

26. Ullrich, O.; Bogen, M.; Lückerath, D.; Rome, E. Co-Operating with Municipal Partners on Indicator Identification and Data Acquisition. Simul. Notes Eur. 2019, 29, 159-168. [CrossRef]

27. Weber, M.; Andrée, D.; Llerena, P. A New Role for EU Research and Innovation in the Benefit of Citizens: Towards an Open and Transformative REI Policy; European Commission: Brussels, Belgium, 2015. Available online: https:/ / ec.europa.eu/futurium/ en/system/files/ged/57_-_rise_-_a_new_role_for_eu_research_and_innovation_in_the_benefit_of_citizens_-_towards_open_ transformativeweber-andree-llerena-new_rolo_research-june15.pdf (accessed on 3 November 2021).

28. European Union. Regulation (EU) No 1290/2013 of the European Parliament and of the Council of 11 December 2013. Available online: https:/ / publications.europa.eu/en/publication-detail/- / publication/3c645e51-6bff-11e3-9afb-01aa75ed71a1/languageen (accessed on 13 September 2021).

29. European Commission. 2018/0224 (COD)_Proposal for a Regulation of the European Parliament and of the CouncilEstablishing Horizon Europe-The Framework Programme for Research and Innovation, Laying Down its Rules for Participation and Dissemination. 2018. Available online: https:/ / eur-lex.europa.eu/legal-content/EN/TXT/?uri=COM:2018:0435:FIN (accessed on 13 September 2021).

30. Poustourli, A. European and International Workshop Agreements: A Brief Example in Security Research Areas. 2016. Available online: https://www.researchgate.net/publication/310242304_European_and_International_Workshop_Agreements_A_Brief_ Example_in_Security_Research_Areas (accessed on 14 September 2021).

31. Lindner, R.; Lückerath, D.; Hernantes, J.; Jaca, C.; Latinos, V.; Peinhardt, K. Bringing Research on City Resilience to Relevant Stakeholders-Combining Co-creation and Standardization in the ARCH project. In Proceedings of the 26th International Conference on Urban Planning, Regional Development and Information Society, Vienna, Austria, 7-10 September 2021. Available online: https:/ /archive.corp.at/cdrom2021/papers2021/CORP2021_104.pdf (accessed on 27 September 2021).

32. ARCH. Project Website. 2021. Available online: https://savingculturalheritage.eu (accessed on 27 September 2021).

33. UNESCO. Managing Disaster Risk for World Heritage. World Heritage Resource Manual. 2010. Available online: https: / / whc.unesco.org/document/104522 (accessed on 2 November 2021).

34. SHELTER. Historic Area Resilience Structure. EU H2020 (GA No. 821282), Deliverable D2.1. 2019. Available online: https: //shelter-project.com/download-document/?deliverables/D2.1.pdf (accessed on 2 November 2021).

35. UNESCO; The World Bank. Culture in City Reconstruction and Recovery. 2018. Available online: https://www.preventionweb. net/files/61959_131856wprevisediipublic.pdf (accessed on 2 November 2021).

36. ICOMOS. Climate Change and Cultural Heritage Working Group. The Future of Our Pasts: Engaging Cultural Heritage in Climate Action; ICOMOS: Paris, France, 2019.

37. Rebollo, V.V.; Latinos, V.; Balenciaga, I.; Roca, R. Good Practices in Building Cultural Heritage Resilience. EU H2020 ARCH (GA No. 820,999). Deliverable D7.2. 2020. Available online: https://savingculturalheritage.eu/fileadmin/user_upload/Deliverables/ ARCH_D7.2_GoodPractices.pdf (accessed on 20 September 2021).

38. Kontokosta, C.; Malik, A. The Resilience to Emergencies and Disasters Index: Applying big data to benchmark and validate neighborhood resilience capacity. Sustain. Cities Soc. 2018, 36, 272-285. [CrossRef]

39. Hernantes, J.; Maraña, P.; Gimenez, R.; Sarriegi, J.; Labaka, L. Towards resilient cities: A maturity model for operationalizing resilience. Cities 2019, 84, 96-103. [CrossRef]

40. Mourshed, M.; Bucchiarone, A.; Khandokar, F. SMART: A Process-Oriented Methodology for Resilient Smart Cities. In Proceedings of the IEEE International Smart Cities Conference, Trento, Italy, 12-15 September 2016. [CrossRef]

41. Lindner, R.; Jaca, C.; Hernantes, J. A Good Practice for Integrating Stakeholders through Standardization-The Case of the Smart Mature Resilience Project. Sustainability 2021, 13, 9000. [CrossRef]

42. Marsella, S.; Marzoli, M. Smart Cities and Cultural Heritage—Protecting historical urban environments from climate change. In Proceedings of the 14th IEEE International Conference on Networking, Sensing and Control, Lamezia, Italy, 16-18 May 2017. [CrossRef]

43. Bernabei, L.; Mochi, G.; Bernardini, G.; Quagliarini, E. Seismic risk of Open Spaces in Historic Built Environments: A matrix-based approach for emergency management and disaster response. Int. J. Disaster Risk Reduct. 2021, 65, 102552. [CrossRef]

44. Blanco Cadena, J.D.; Moretti, N.; Salvalai, G.; Quagliarini, E.; Re Cecconi, F.; Poli, T. A New Approach to Assess the Built Environment Risk under the Conjunct Effect of Critical Slow Onset Disasters: A Case Study in Milan, Italy. Appl. Sci. 2021, 11, 1186. [CrossRef]

45. Maraña, P.; Eden, C.; Eriksson, H.; Grimes, C.; Hernantes, J.; Howick, S.; Labaka, L.; Latinos, V.; Lindner, R.; Majchrzak, T.A.; et al. Towards a resilience management guideline-Cities as a starting point for societal resilience. Sustain. Cities Soc. 2019, $48,101531$. [CrossRef]

46. Maresch, S.; Lindner, R. Proposal for CEN Workshop Agreements. EU H2020 SMR (GA No. 653569). Deliverable D6.4. 2017. Available online: http://smr-project.eu/fileadmin/user_upload/Documents/Resources/WP_6/2017-11-30_D_6.4_Proposal_ for_CEN_Workshop_Agreements.pdf (accessed on 13 September 2021).

47. De Jong, M.; de Buck, A.; Balder, M.; Bogen, M. RESIN Deliverable 5.1/2.2: Standardization in Urban Climate Adaptation. EU H2020 RESIN (GA No. 653522). Deliverable D5.1/2.2. 2018. Available online: https://resin-cities.eu/fileadmin/user_upload/ Papers/RESIN-D5.1_Standardization_in_urban_climate_adaptation_NEN_30102018.pdf (accessed on 20 September 2021). 
48. CEN. Website of CEN Boss. 2021. Available online: https://boss.cen.eu/developingdeliverables/CWA/Pages/ (accessed on 20 September 2021).

49. Linkov, I.; Palma-Oliveira, J. An Introduction to Resilience for Critical Infrastructures. In Resilience and Risk; Linkov, I., PalmaOliveira, J., Eds.; Springer: Amsterdam, The Netherlands, 2017; pp. 3-17.

50. Zuccaro, G.; Leone, M.; Martucci, C. Future research and innovation priorities in the field of natural hazards, disaster risk reduction, disaster risk management and climate change adaptation: A shared vision from the ESPREssO project. Int. J. Disaster Risk Reduct. 2020, 51, 101783. [CrossRef]

51. Robertson, J. The three Rs of action research methodology: Reciprocity, reflexivity and reflection-on-reality. Educ. Action Res. 2000, 8, 307-326. [CrossRef]

52. Chein, I.; Cook, S.; Harding, J. The field of action research. Am. Psychol. 1948, 3, 43-50. [CrossRef] [PubMed]

53. Ottosson, S. Participation action research: A key to improved knowledge of management. Technovation 2003, 23, 87-94. [CrossRef]

54. Cook, B.; Atkinson, M.; Chalmers, H.; Comins, L.; Cooksley, S.; Deans, N.; Fazey, I.; Fenemor, A.; Kesby, M.; Litke, S.; et al. Interrogating participatory catchment organisations: Cases from Canada, New Zealand, Scotland and the Scottish-English Borderlands. Geogr. J. 2013, 179, 234-247. [CrossRef]

55. Cvitanovic, C.; Howden, M.; Colvin, M.; Norströmd, A.; Meadow, A. Maximising the benefits of participatory climate adaptation research by understanding and managing the associated challenges and risks. Environ. Sci. Policy 2019, 94, 20-31. [CrossRef]

56. Yang, R.J. An investigation of stakeholder analysis in urban development projects: Empirical or rationalistic perspectives. Int. J. Proj. Manag. 2014, 32, 838-849. [CrossRef]

57. Latinos, V.; Chapman, E. Guideline on ARCH Co-Creation Approach. EU H2020 ARCH (GA No. 820,999). Deliverable D3.1. 2020. Available online: https:/ / savingculturalheritage.eu/fileadmin/user_upload/Deliverables/20201130_ARCH_D3.1.pdf (accessed on 20 September 2021).

58. DIN. Website on the Principles on Standards Work. 2021. Available online: https://www.din.de/en/about-standards/dinstandards / principles-of-standards-work (accessed on 21 September 2021).

59. Lückerath, D.; Pannaccione Apa, M. ARCH State-of-the-Art Report 3 Building Back Better. EU H2020 ARCH (GA No. 820999), Deliverable D7.1(3). 2019. Available online: https:/ / savingculturalheritage.eu/fileadmin/user_upload/Deliverables/ARCH_D7 .1_SotA_report_3_building_back_better.pdf (accessed on 20 September 2021).

60. Climate-ADAPT. The Urban Adaptation Support Tool—Getting started. 2021. Available online: https://climate-adapt.eea. europa.eu/knowledge/tools/urban-ast/step-0-0 (accessed on 28 September 2021).

61. Bours, D.; McGinn, C.; Pringle, P. Monitoring E Evaluation for Climate Change Adaptation and Resilience: A Synthesis of Tools, Frameworks and Approaches; SEA Change Community of Practice and UK Climate Impacts Programme: Oxford, UK, 2014. Available online: http:/ /www.managingforimpact.org/sites/default/files/resource/2014_05_15_sea_change_ukcip_synthesis_ report_2nd_edition.pdf (accessed on 28 September 2021).

62. CEN. Project Plan for CWA 17727. 2021. Available online: https://ftp.cencenelec.eu/CEN/News/WS/2021/ARCH/CEN-WSARCH_Project-Plan.pdf (accessed on 29 September 2021).

63. Silva, S.; Guenther, E. Setting the research agenda for measuring sustainability performance-Systematic application of the world café method. Sustain. Account. Manag. Policy J. 2018, 9, 455-469. [CrossRef] 